\title{
Enteral nutrition
}

\author{
D. B. A. SILK \\ M.D., F.R.C.P. \\ Department of Gastroenterology and Nutrition, Central Middlesex Hospital, London, NW10 7NS
}

This issue attests to the fact that Sir Francis Avery Jones has had wide based interests during his 50 years in clinical medicine. In recent years he has become one of the major forces behind the promotion of clinical nutrition. He has directed much effort to bridging the gap that has for so long existed between the non-medical academic centres of research in nutrition and the practising clinician. It is no coincidence that several major recommendations made by the British Nutrition Foundation Task Force (Avery Jones, 1983a) on which he was a very active participant, reflect completely his longstanding views about what needs to be done to improve the nutritional management of patients.

Sir Francis has always believed that there has been a need for medically qualified personnel to participate actively in research on clinical nutrition, and over the years research groups based in his Unit at Central Middlesex Hospital have worked in this area. He has promoted the teaching of nutrition in both health and disease at both the undergraduate and postgraduate stages of medical training. It was clear when I arrived at Central Middlesex Hospital in 1978 , that my own personal research interests in no way conflicted with those existing within the Unit, and with Sir Francis Avery Jones' encouragement, we have merely enlarged an existing basic physiological and clinical research programme. Moreover, it was Sir Francis who persuaded Dr J. J. Misiewicz and myself to alter the name of our department from that of Gastroenterology alone to Gastroenterology and Nutrition.

One of Sir Francis' beliefs (Avery Jones, 1983b) has been the need in district hospitals for one department to take the lead in organizing a 'nutrition team' to provide a nutrition advisory service for the hospital and to co-ordinate with the district medical services, thereby emphasizing the importance of nutrition in the community and in postgraduate education - this I hope we have been able to achieve.

Sir Francis has provided encouragement for all the work we have done in the last 5 years, and especially for our efforts in the field of enteral nutrition, I have therefore chosen this subject for his Festschrift. The ensuing discussion will include not only an update on practical techniques involved in feeding patients enterally but also reference will be given to some of the problems that still exist in defining what constitutes 'malnutrition' in the hospitalized patient as well as to the problems that exist in defining the nutritional requirements of the individual patient.

\section{Incidence and diagnosis of protein calorie malnutri- tion}

Recent studies have suggested that $20-50 \%$ of hospitalized patients have some evidence of protein calorie malnutrition (Bristian et al., 1974; Hill et al., 1977). These findings in turn indicate that awareness of the nutritional status of patients is a neglected area of clinical management and it follows that nutritional assessment is the first essential step in the nutritional care of any patient. Few problems arise in recognising the grossly malnourished patient in whom weight loss is marked, hypoproteinaemic oedema is present, muscle wasting extreme, and serum albumin levels are lower than $25 \mathrm{~g} / \mathrm{l}$. Problems may arise, however, in reaching the diagnosis in the fitter looking patient who at first sight may even look obese (Fig. 1). During the last few years a battery of clinical, biochemical, haematological and immunological tests have been described as aids to reaching a diagnosis of protein calorie malnutirition (Table 1).

\section{Clinical history}

A routine clinical history usually neglects the nutritional intake. We have been surprised to find that patients randomized to controlled clinical trials of enteral nutrition have had a markedly reduced nutritional intake for as long as 3 weeks before nutritional support was instituted (Jones et al., 1983; Keohane et al., 1983).

\section{Clinical examination}

Many nutritional deficiencies are unaccompanied 
TABLE 1. Diagnosis of protein calorie malnutrition (after Silk 1983)

\begin{tabular}{|c|c|}
\hline Measurement & $\begin{array}{l}\text { Values suggestive of } \\
\text { protein calorie } \\
\text { malnutrition }\end{array}$ \\
\hline $\begin{array}{l}\text { Clinical and dietary history } \\
\text { Clinical examination } \\
\text { Body weight }\end{array}$ & $\begin{array}{l}\text { see text } \\
\text { Loss }>10 \% \text { normal } \\
\text { weight }\end{array}$ \\
\hline $\begin{array}{l}\text { Anthropometric measurement } \\
\text { Mid-arm circumference } \\
\text { Mid-arm muscle circumference } \\
\text { Skinfold thickness }\end{array}$ & $\begin{array}{l}<23 \mathrm{~cm} \delta<22 \mathrm{~cm} q \\
<19 \mathrm{~cm} \delta<17 \mathrm{~cm} q \\
\text { see Silk }(1983)\end{array}$ \\
\hline $\left.\begin{array}{l}\text { Measurements of protein stores } \\
24 \mathrm{hr} \text { urinary creatinine } \\
\text { Creatinine height index } \\
\text { 3-methyl histidine excretion } \\
\text { Circulating hepatic proteins }\end{array}\right\}$ & see text \\
\hline $\begin{array}{l}\text { Albumin } \\
\text { Transferrin } \\
\text { Prealbumin } \\
\text { Retinol-binding protein }\end{array}$ & $\begin{array}{l}<35 \mathrm{~g} / 1 \\
<2 \mathrm{~g} / 1 \\
<200 \mathrm{mg} / 1 \\
<100 \mathrm{mg} / 1\end{array}$ \\
\hline $\begin{array}{l}\text { Immunological testing } \\
\text { Lymphocyte count } \\
\text { Delayed hypersensitivity skin } \\
\text { testing }\end{array}$ & $\begin{array}{l}<200 / \mathrm{mm}^{3} \\
\text { see Silk (1983) }\end{array}$ \\
\hline
\end{tabular}

by physical signs, but clinical examination should always be carried out. Angular stomatitis, increased capillary fragility, anaemia, muscle wasting and oedema signify severe nutritional deficiency. Loss of body weight may provide the first clue that a patient is malnourished and we attach importance to a loss of more than $10 \%$ of normal body weight. We have found ideal weight for height and body mass index to be of more limited value.

\section{Anthropometric measurements}

Anthropometric measurements, such as arm muscle circumference and triceps skinfold thickness (TSF) and derivatives of these arm measurements have gained increasing importance in establishing the protein and fat reserves of hospitalized patients. An assessment of muscle mass can be gained by means of the midarm muscle circumference (MMC). This is calculated from the midarm circumference and triceps skinfold thickness, from the formula: MMC $=$ midarm circumference minus $(\pi \times$ triceps skinfold thickness). Erroneous measurements can be obtained in oedematous patients in whom correlations between changes in body nitrogen and midarm circumference and midarm muscle circumference are not exact (Collins, McCarthy and Hull, 1979). Although of limited value in obese patients and those with peripheral oedema, body fat content can be estimated simply with Harpenden skin callipers to measure skinfold thickness at four sites (James, 1982).

\section{Measurements of protein stores}

Malnutrition is associated with a reduction in total body protein content and, in clinical practice, mea- $\underset{\vec{P}}{\vec{D}}$ surements of muscle mass have been regarded as? relatively sensitive measures of total body protein. Midarm muscle circumference, as described above, is $\overline{\bar{D}}$ the simplest method available. Other methods for $\mathbb{\mathbb { D }}$ assessing protein stores, including measurements of $24 \mathrm{hr}$ urinary creatinine excretion, the creatinine os height index, neutron activation analysis for whole $\vec{O}$ body nitrogen, whole body counts of potassium and $\overrightarrow{-}$ isotope techniques for measuring total exchangeable $\vec{\omega}_{\tilde{O}}$ potassium and water content have all been described (for review, see Silk, 1983) but have not found a place in our routine clinical practice.

A great deal of interest has surrounded the measurement of 3-methylhistidine to assess the de- $\supset$ gree of muscle breakdown. When released 3-methylhistidine is not re-utilised in protein synthesis and is $\circlearrowright$ excreted unchanged in the urine. The excretion of 4.2 을 $\mu \mathrm{mol}$ of 3-methylhistidine represents the breakdown of $1 \mathrm{~g}$ of mixed muscle protein (Munro, 1978).

\section{Indirect measurements of protein synthesis rates}

Numerous claims have been made that measurement of circulating hepatic proteins provides usef information about nutritional status, and response to nutritional support. In the absence of parenchyms liver disease and proteinuria, the serum albumin concentration provides useful information about the nutritional state, values below $30 \mathrm{~g} / 1$ indicating moderate-to-severe malnutrition. Although claims have been made to its value in monitoring the $\AA$ response to treatment, albumin has a long half-life, $\overrightarrow{\vec{O}}$ and in our experience (Jones et al., 1983), as well as that of others, shows a poor response to short-term nutritional support (Shetty et al., 1979).

Transferrin has a half-life of 8 days, shorter than albumin, and plasma levels are reduced in protein 3 calorie malnutrition (Ingenbleek et al., 1975). Its usefulness in clinical practice is limited by co-existing iron deficiency states which promote its synthesis, $\delta$ and in patients who are infected and undergoing stress as part of the 'acute phase' protein response.

Thyroxine-binding prealbumin (TBPA) and reti- $\supset$ nol binding protein (RBP) are two hepatic proteins whose plasma levels are also reduced in obvious $N$ protein calorie malnutrition (Ingenbleek et al., 1975). TBPA has a half-life of 2 days, and RBP of $12 \mathrm{hr} N$ and as such both would be expected to respond to $\underset{\omega}{N}$ changes in nitrogen and energy input as occur during 0 the nutritional therapy of malnourished patients. Studies indicate, though, that TBPA levels are more $\stackrel{\odot}{\Phi}$ sensitive to changes in energy rather than nitrogen $\stackrel{?}{?}$ intake. Plasma levels of RBP on the other hand alter $D$ rapidly in response to changes in both energy and 
nitrogen intake (Shetty et al., 1979) so that if close monitoring of nutritional support is required in the clinical setting, plasma RBP, when measured regularly, should provide valuable information.

\section{Immunological testing}

Protein calorie malnutrition has now frequently been shown to be associated with impaired immunocompetence (Law, Dudrick and Abdon, 1979) and a reduction in total peripheral lymphocyte count to below $1200 / \mathrm{mm}^{3}$ is seen in obvious protein calorie malnutrition.

Negative skin testing with ubiquitous antigens has been frequently reported in patients with protein calorie malnutrition and skin testing has been proposed as a practical aid to the diagnosis of protein calorie malnutrition (Pietsch, Meakins and Maclean, 1977).

We have confirmed that patients with obvious protein calorie malnutrition have negative skin tests (i.e. are anergic), just as have patients with less obvious clinical malnutrition. We have not, however, been able to confirm the observations of others (Pietsch et al., 1977) that effective nutritional support is associated with reversal of the anergic state. In this respect it is important for the reader to be aware of other data showing that ageing, cancer, sarcoidosis, infection, shock, acute trauma and zinc deficiency have all been shown to be associated with anergy per se, irrespective of nutritional status (see Silk, 1983).

\section{Expectations of the nutritional measurements}

Ideally, the nutritional measurements discussed above should provide not only information about the diagnosis of protein calorie malnutrition, but serial measurements should also provide information about the effectiveness of nutritional support. Finally, it would be of immense value if clinically useful measures of malnutrition could be established that would reliably predict the likely occurrence of postoperative complications. It is our feeling however, that an unreasonable burden of expectation has been placed on the use of these nutritional measurements.

\section{Aids to diagnosis of protein calorie malnutrition}

At the outset of our nutritional programme we assiduously measured all, or most, of the nutritional measurements, and decisions as to whether to institute nutritional support were based on these results. We began to place less reliance on these tests when it was shown that there was close agreement between assessments of nutritional status based solely on the experience of an experienced clinician as compared with the use of a large battery of nutritional

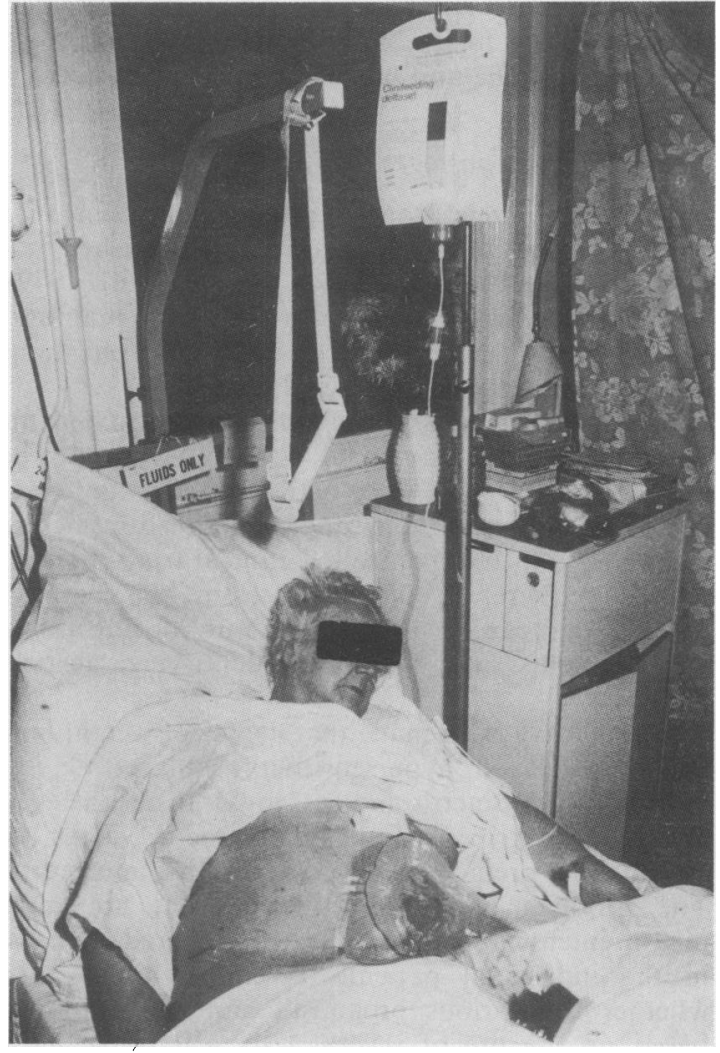

FIG. 1. Severe protein calorie malnutrition, but less obvious clinically (female aged 65 years). Wound dehiscence and enterocutaneous fistula following second laparotomy for recurrent small bowel obstruction. Note apparent obesity. Serum albumin $24 \mathrm{~g} / 1$. Patient is receiving nutritional support via the enteral route.

measurements (Baker et al., 1982). Moreover, as we gained more experience, we began to realise that one of the major roles of nutritional support is to prevent the development of protein calorie malnutrition. Consequently, our decisions as to whether to institute nutritional support are now influenced more by previous dietary history and the natural history of the primary disease process in respect of future nutritional intake than by nutritional measurements. In practical terms, therefore, we currently place very little emphasis on nutritional measurement.

\section{Monitoring treatment}

Many authors have advocated serial nutritional measurements as a means of monitoring nutritional therapy (Law et al., 1973; Spanier et al., 1976; Meakins et al., 1977). We have not been impressed however, with the clinical significance of changes that occur during treatment, and do not advocate the routine measurement of all those listed in Table 1. 
We place more emphasis on monitoring nitrogen balance during treatment and the early detection of clinical metabolic and haematological side effects.

\section{Prediction of postoperative morbidity}

In surgical circles, there is growing enthusiasm for vigorous nutritional support of malnourished patients about to undergo major surgery (Hill, 1979). This argument is based on the premise that malnourished patients have more postoperative complications and even an increased risk of dying.

In order to demonstrate significant clinical benefits of pre-operative nutritional support, it would be necessary to identify those patients who would be at risk of developing postoperative complications before randomization into controlled clinical trials. Several groups are therefore currently assessing the degree of reliance that can be placed on the use of nutritional measurements as a means of identifying 'at risk' patients.

Claims have been made that degree of weight loss, negative delayed hypersensitivity skin testing, reduced anthropometric indices, low transferrin levels and reduced grip strength dynamometry values are all reliable predictors of postoperative morbidity. The problem has been however, that no single measurement can be reliably used as a predictive test in the individual patient. It remains to be seen whether the various prognostic nutritional indices based on the use of several tests will prove more successful at reliably predicting whether the individual patient is at risk of developing postoperative complications.

\section{Indications for providing nutritional support}

The indications for instituting nutritional support have not been properly elucidated. One of the major reasons for this has been the lack of properly performed clinical trials that include the withholding of specific nutritional therapy from one group of patients. The difficulties in identifying 'at risk' patients with, for example, a high risk of developing postoperative complications has often led to the inclusion of large numbers of normally, or nearly normally nourished, rather than malnourished patients in clinical nutrition studies. This has made the interpretation of the benefits of nutritional support virtually impossible. Finally, when differences are noted betweeen treatment and control groups it is a matter of opinion whether they are clinically significant; for example, reducing hospital in-patient stay after surgery by a short period can hardly be cited as being a clinically significant benefit of nutritional support.

Guidelines for assessing the indications for provid- ing nutritional support used at Central Middlesex are summarised in Table 2.

TABLE 2. Indications for nutritional support

1. Obvious gross malnutrition: albumin $<30 \mathrm{~g} / \mathrm{l}$; marked weigh loss; muscle wasting; oedema

2. Nutritional measurements suggestive of protein calorie malnu@ trition-dietary history shows impaired nutrient intake for onछ्छ week or more

3. Medical and surgical disorders likely to result in protein calori malnutrition if nutritional support withheld

In many previous reviews it has of course been traditional to categorise those clinical conditions that' may be frequently associated with protein caloriemalnutrition and to imply that patients with theseco conditions are those likely to require nutritional support. Such an approach however, is a gross oversimplification of the problems that arise when decid-s ing whether or not to institute nutritional support ${ }_{\vec{C}}$ because, as one's experience of clinical nutritionalo broadens, one realises that almost all medical andळ surgical conditions can be accompanied by protein 3 calorie malnutrition. Despite the difficulties that exist in defining the indications for nutritional suppogt, $\vec{c}$ clinical trials and clinical experience have highlighted a number of areas where clear benefits haffe been obtained (Table 3).

TABLE 3. Specific indications for nutritional support

Definite benefit
Management of short bowel syndrome
Intestinal fistulas-without distal obstruction
Intra abdominal sepsis
Major burns
Major sepsis
Multiple injuries involving viscera
Pancreatic abscess/pseudocyst/trauma/fistula
Possible benefit
Acute pancreatitis
Inflammatory bowel disease
Pre-operatively*-major surgery including cancer surgery
Post-operatively-major surgery and complications

*See text-value of nutritional measurements in predicting post-operative morbidity.

\section{Assessment of nutritional requirements (Table 4)}

Any attempt to correct the nutritional deficits in under-nourished or injured patients must include the provision of a readily utilised energy substrate, $\stackrel{\infty}{\rightarrow}$ nitrogen for protein synthesis, fluid, electrolytes, 0 vitamins and haematinics. 
TABLE 4. A guide to the daily nutritional requirements for enteral and parenteral nutrition

\begin{tabular}{lc}
\hline $\begin{array}{l}\text { Nitrogen } \\
\text { Energy }\end{array}$ & $\begin{array}{l}8-20 \mathrm{~g} \\
6270-16720 \mathrm{~kJ} \\
(1500-4000 \mathrm{cal})\end{array}$ \\
$\begin{array}{l}\text { Electrolytes and } \\
\text { trace elements } \\
\text { Sodium }\end{array}$ & $70-150 \mathrm{mmol}$ \\
Chloride & $70-220 \mathrm{mmol}$ \\
Potassium & $50-100 \mathrm{mmol}$ \\
Calcium & $5-10 \mathrm{mmol}$ \\
Magnesium & $5-20 \mathrm{mmol}$ \\
Phosphate & $30-50 \mathrm{mmol}$ \\
Fluoride & $50 \mu \mathrm{mol}$ \\
Manganese & $2-4 \mathrm{mg}$ \\
Copper & $1.5-3.0 \mathrm{mg}$ \\
Zinc & $10-20 \mathrm{mg}$ \\
Iron & $10-15 \mathrm{mg}$ \\
Selenium & $100-200 \mu \mathrm{g}$ \\
Iodine & $10-200 \mu \mathrm{g}$ \\
Chromium & $5-10 \mu \mathrm{g}$ \\
\hline
\end{tabular}

\section{Energy and nitrogen (Table 5)}

There is a close relationship between energy and nitrogen balances so that the requirements of the two can be considered together. In a normal active man, positive nitrogen balance is achieved with a nitrogen intake of 8-9 g/24 hr. Non-protein energy requirements are in the region of $1338 \mathrm{~kJ} / \mathrm{g}(320 \mathrm{cal} / \mathrm{g})$ of nitrogen. As the metabolic expenditure of a starved, re-feeding patient is low, nitrogen equilibrium can be attained with a nitrogen intake of $7 \mathrm{~g} / \mathrm{day}$, with a non-protein requirement of $1200 \mathrm{~kJ} / \mathrm{g}(250 \mathrm{cal} / \mathrm{g})$ of nitrogen. When the metabolic rate is increased after injury or during a febrile illness, relatively more nitrogen is needed to produce positive nitrogen balance. Ideally nitrogen requirements should be estimated from direct measurements of nitrogen losses in urine, stool and ostomy or fistula effluents.

TABLE 5. Approximate requirements for energy and nitrogen*

\begin{tabular}{|c|c|c|c|}
\hline & Non-catabolic & Intermediate & Catabolic \\
\hline $\begin{array}{l}\text { Nitrogen (g/day) } \\
\text { Energy kJ/day } \\
\text { (cal/day) } \\
\text { Non-protein energy } \\
\text { in } \mathbf{k J} / \mathrm{g} \\
\text { (cal/g) of nitrogen }\end{array}$ & $\begin{array}{c}7.5 \\
9600(2000) \\
1200(250)\end{array}$ & $\begin{array}{c}14 \\
14,400(3000)\end{array}$ & $\begin{array}{c}25 \\
19,200(4000)\end{array}$ \\
\hline
\end{tabular}

*After Woolfson (1978).

In practice the methods are cumbersome, time consuming and costly. With the exception of patients with protein-losing enteropathies and fistulae, reliable estimations of nitrogen losses (NL) in $\mathrm{g} / 24 \mathrm{hr}$ can be calculated from the following formula $\mathrm{NL}=$ (mmol urinary urea $/ 24 \mathrm{hr} \times 0.028)+2$, where the factor of 2 is added to take into account constant non- urea urinary nitrogen as well as faecal and skin losses. Simple corrections for proteinuria and rising blood urea values in renal failure patients have been described.

\section{Electrolytes}

Attention should be paid to correcting electrolyte imbalance in all patients receiving nutritional therapy; the values shown in Table 4 can be considered only as a guide to requirements. Potassium losses occur in a fixed ratio to nitrogen losses, so at least 5 mmol potassium should be administered with each gram of nitrogen.

As a general principle, biological fluids should be collected from appropriate orifices of sick patients (e.g. gastric aspirates, fistula and drain effluents, urine, diarrhoea, faeces) and analysed for electrolyte content. Hypophosphataemia is a common complication of parenteral (intravenous) nutrition; and therefore at least $30 \mathrm{mmol}$ phosphate must be administered daily.

\section{Minerals}

Mineral deficiencies in patients receiving longterm nutritional support have been well documented. Unfortunately the minimal daily requirements of most minerals are not known with any certainty, so that the values for manganese, copper, zinc and selenium given in Table 4 are, at best, approximate, and further research will almost certainly indicate that additional trace metals should be added to this list.

\section{Vitamins}

Vitamins are necessary for the utilisation of nutritional components and vitamin deficiencies can occur rapidly in the debilitated state. Vitamin supplements should be given as soon as nutritional support is started.

\section{Methods of providing nutritional support (Table 6, 7)}

It is important to emphasise that when gastrointestinal function is normal attempts should be made to institute enteral rather than parenteral nutrition. Ideally the patient should be fed orally, either with whole or liquidised food, or with the addition of palatable supplements. If this is not possible liquid feeds can be administered via a naso-enteric tube. Some patients requiring nutritional therapy have a gastrostomy or jejunostomy and nutrition can be administered via these routes. Only if these methods fail should nutrients be provided via the parenteral route. 
TABLE 6. Factors limiting achievement of nutritional objectives

\begin{tabular}{l} 
Most common \\
Sepsis \\
Trauma \\
Severe fractures \\
Major visceral injury \\
Major burns \\
Major operations \\
Immobility \\
Bedbound \\
Splinting of fractures \\
Neurological causes \\
Muscle relaxant drugs in intensive care \\
Pain \\
Common \\
Technique \\
Insufficient energy supply \\
Insufficient amino-nitrogen supply \\
Insufficient co-factors for nitrogen utilisation \\
Fluid balance \\
Inability to tolerate volume required for nutritional requirements \\
Unusual \\
Metabolic \\
Hyperglycaemia unresponsive to insulin \\
Hyponatraemia due to inappropriate anti-diuretic hormone secre- \\
tion \\
Occult losses of protein \\
Low ambient temperature \\
\hline
\end{tabular}

\section{Enteral nutrition}

Once the decision is made to provide nutritional support via the enteral route, the best formulation to meet the nutritional needs of the individual patient must be selected. There are now a good many commercially available enteric diets in the U.K. and important differences exist in respect of their nutritional components.

\section{Diet formulation}

\section{Diets for patients with normal gastrointestinal function}

Patients with normal gastrointestinal function are capable of assimilating whole protein and unhydrolysed triglyceride. Enteric diets for these patients should therefore contain whole protein as the nitrogen source, and a mixture of triglycerides and carbohydrate as the energy source. Our recent physiological studies indicate that high molecular weight glucose polymers are the most suitable carbohydrate energy source (Jones et al., 1981). Controversy exists as to what constitutes the optimum nonprotein energy to nitrogen ratio of these diets. Since the nitrogen and energy requirements of different patients varies (Table 5), a ratio of $150 \mathrm{kcal} / \mathrm{g} \mathrm{N}$ would appear a reasonable compromise. Enteric diets for those patients with normal gastrointestinal function should contain sufficient electrolytes, trace elements and vitamins to satisfy nutritional requirements.
TABLE 7. Methods of providing nutritional support

\begin{tabular}{ll}
\hline Route & Nutritional source \\
\hline Oral feeding & $\begin{array}{l}\text { Food } \\
\text { Liquidised food } \\
\text { Palatable enteral diet } \\
\text { Enteral diets }\end{array}$ \\
$\begin{array}{l}\text { Tube feeding } \\
\text { Nasogastric } \\
\text { Nasoduodenal } \\
\text { Nasojejunal }\end{array}$ & \\
Gastrostomy & Liquidised food \\
Eejunostomy & Enteral diet \\
Parenteral nutrition & \\
\hline
\end{tabular}

2. Diets for patients with impaired gastrointestinaţ
function

In a small group of patients, nutrient assimilatione may be impaired by insufficient luminal nutrient $\checkmark$ hydrolysis or because the functional absorptive capacity of the intestine is so reduced as not to be able to cope with the quantities of nutrients presentedto it for absorption. In these circumstances it follows that nutrients should be presented to the gut in predigested form, and indeed to ensure that the maximal possible absorption is achieved the predigested nutrients should ideally be presented in the form in which they are absorbed fastest in the normato clinical setting.

Conditions in which luminal nutrient hydrolysis severely impaired include severe exocrine pancreatios insufficiency, obstructive jaundice and the short bowel syndrome. The functional absorptive capacityo of the intestine may be severely reduced in the shor $B$ bowel syndrome and in clinical conditions character $\overrightarrow{\overrightarrow{0}}$ ized by a severe and extensive mucosal lesion (coelia@ disease, severe Crohn's disease). These then becomer the indications for the use of predigested diets. The्e. old term 'elemental diet' is a misnomer. Used initially to describe the early free amino-acid and glucose 3 containing diets, it has later been used to describe alb the other diets containing predigested nutrients that were far from 'elemental' in design.

The use of 'elemental' diets has been advocated in? a variety of clinical conditions (Russell, 1975) includo ing the management of gastrointestinal fistulae $\gg$ inflammatory bowel disease, the nutritional manage ment of patients with gastrointestinal cancer and those with severe maldigestion and malabsorption? and, finally, their use as a means of pre-operative bowel preparation has also been suggested. In brilliant exposé of the myths surrounding the indicaల tions and uses of 'elemental' diets, Koretz and Meyeb (1980) point out that there is very little controlleck data to support any of these claims. In our unit, wẹ? have just shown (Jones et al., 1983) that there is noo evidence for the superiority of 'elemental' overo 
polymeric diets containing whole protein as a nitrogen source in the management of malnourished patients with normal gastrointestinal function, an observation that was also noted during an investigation of the efficacy of 'elemental' and polymeric diets in unconscious patients with head injury (Jones et al., 1980).

The nitrogen source of these predigested diets should, in the light of our current knowledge, consist of oligopeptides rather than free amino acids. Partial enzymic hydrolysates of whole protein constitute the most suitable peptide-based nitrogen source, although the optimum starter protein, hydrolysis procedure and peptide chain length have yet to be defined. Because our intestinal perfusion studies indicate the purified high molecular weight glucose polymers are assimilated in the absence of luminal amylase activity (Jones et al., 1981) these should probably constitute the carbohydrate fraction of the energy source.

Because these diets are probably indicated in conditions in which luminal fat digestion is impaired, they should not contain large amounts of triglyceride-based energy source. It is not completely clear as to whether large quantities of medium-chain triglycerides (MCT) are absorbed in the absence of luminal hydrolysis, so medium-chain triglycerides should probably not be included in these diets. The diets should contain at least $4 \%$ of their total energy content as linoleic acid, however, to prevent the development of essential fatty acid deficiency, as well as sufficient electrolytes, trace elements and vitamins to satisfy the requirements of the average malnourished patient.

\section{Enteral diets currently available}

Before the recent resurgence of interest in enteral nutrition, those patients with normal gastrointestinal function who did receive nutritional support were fed tube feeds prepared in the hospital dietetic department. Although these tube feeds are cheap, the preparation of large quantities places a significant burden on the workload of the dietetic department, which is the major reason why they are not routinely used in our hospital. Care should be taken to ensure that these diets are prepared under reasonably sterile conditions, as problems with infection have been well documented (Casewell, 1979) and there is now controlled data to show that the incidence of diarrhoea is higher when 'home brew', rather than commercial diets, are used for enteral feeding (Keighley et al., 1982).

Some of the more widely used polymeric and predigested 'elemental diets' are listed in Table 8.

\section{Routes of administration}

\section{Oral feeding}

When the patient is able to swallow, but still unable to eat normal food (e.g. because of an oesophageal stricture), a liquid diet can be provided from any hospital diet kitchen. The large volume of fluid required to liquidize whole food may make this type of supplement unacceptable to some patients.

The palatable standard enteric diets and the elemental diets listed in Table 8 are suitable for oral feeding, both as a means of supplementing an inadequate intake of normal food and as the sole means of nutritional support.

If it is planned to use the proprietary enteric diets as the sole means of nutritional support, we prefer to administer the diets via a nasoenteric tube, because we find it easier to document and control intake precisely. Another reason is that the patients find that most of the diets are not as palatable as the manufacters claim and excessive nursing time is taken up cajoling patients to ingest the desired quantities.

\section{Nasogastric tube feeding}

Patients who cannot swallow, or who will not tolerate oral feeding, can be fed via a nasogastric tube. The time-honoured method of tube feeding has been to place a large-bore Ryle's tube into the stomach and intermittently to instil up to $200 \mathrm{ml}$ liquid feed, having first aspirated the gastric residue. This method is probably responsible for the poor reputation of enteral feeding, as the incidence of side effects, namely diarrhoea, aspiration pneumonia and oesophageal ulceration, has been unacceptably high.

Major new developments have taken place in this field and most of these problems have now been circumvented. Enteric feeds (Fig. 2) can be administered from containers by gravity infusion via narrow bore feeding tubes, most of which are inserted, with the aid of an introducer, into the stomach. These finebore tubes are more comfortable than the older wider bore tubes and their use has not so far been associated with oesophageal erosions, ulcers or strictures. Although easy to pass, the final position should be checked radiologically or by insufflating $5 \mathrm{ml}$ air and auscultating over the epigastrium to ensure that the feeding tube has been positioned in the stomach and not the bronchial tree.

As Fig. 3 shows, there are now a large number of fine-bore feeding tubes on the market. Broadly speaking there are the simple unweighted tubes or feeding tubes with weighted tips. In our experience, in routine clinical use, the more expensive weighted tubes offer few advantages over the simple un- 
TABLE 8. Proprietary enteral diets

\begin{tabular}{|c|c|c|c|c|}
\hline & $\begin{array}{c}\text { Flavouring } \\
\text { necessary }\end{array}$ & Presentation & $\begin{array}{l}\text { Osmolality } \\
\mathrm{mosmol} / \mathrm{kg}\end{array}$ & $\begin{array}{c}\text { Non-protein } \\
\text { energy/Nitrogen } \\
\text { ratio }(\mathrm{kcal} / \mathrm{g} \mathrm{N})\end{array}$ \\
\hline \multicolumn{5}{|l|}{ Polymeric diet* } \\
\hline Build up (Carnation) & No & Powder & 575 & 100 \\
\hline Clinifeed 400 (Roussel) & No & Liquid & 426 & 142 \\
\hline Clinifeed Favour (Roussel) & No & Liquid & 403 & 142 \\
\hline Clinifeed Iso (Roussel) & No & Liquid & 321 & 200 \\
\hline Ensure (Abbott) & No & Liquid & 430 & 154 \\
\hline $\begin{array}{l}\text { Fortison standard } \\
\text { (Cow and Gate) }\end{array}$ & No & Liquid & 300 & 131 \\
\hline $\begin{array}{l}\text { Fortison Energy-Plus } \\
\text { (Cow and Gate) }\end{array}$ & No & Liquid & 410 & 167 \\
\hline Isocal (Mead Johnson) & Yes & Liquid & 350 & 170 \\
\hline Nutrauxil (Kabivitrum) & No & Liquid & 386 & 140 \\
\hline Trisorbon (BDH) & No & Powder & 400 & 130 \\
\hline \multicolumn{5}{|l|}{$\begin{array}{l}\text { Chemically defined } \\
\text { (elemental diets) }\end{array}$} \\
\hline Flexical (Mead Johnson) & Yes $^{\dagger}$ & Powder ${ }^{\ddagger}$ & 580 & 256 \\
\hline Nutranel (Roussel) & $\mathrm{Yes}^{\dagger}$ & Powder $\neq$ & 550 & 131 \\
\hline Vivonex HN (Eaton) & Yes $^{\dagger}$ & Powder ${ }^{x}$ & 830 & 121 \\
\hline
\end{tabular}

*All have whole protein as nitrogen source.

tin the opinion of the author.

‡Oligopeptate nitrogen source.

${ }^{\star}$ Free amino acid nitrogen source.

TABLE 9. Complications of enteral nutrition

Tube insertion
Oesophagitis
Oesophageal erosions
Oesophageal stricture
Tube misplacement
Tube withdrawal
Gastrointestinal side effects
Diarrhoea
Abdominal distension
Abdominal pain
Intussusception
Metabolic complications
Hyperglycaemia
Hypokalaemia
Hypomagnesaemia
Hypocalcaemia
Hypophosphataemia
Low zinc levels
Low red cell folate
Abnormalities of liver function
Intravenous administration of enteric feeds
Regurgitation and aspiration

weighted and open-ended feeding tubes. There are three clinical areas, however, where we have noted a distinct advantage (Keohane and Silk, 1983).

1. Nasogastric intubation of patients already intubated with an endotracheal tube.

2. Intubation of patients with oesophageal strictures in whom endoscopic intubation with unweighted tubes has failed.

3. Nasoenteric feeding (see below).

\section{Endoscopic tube placement}

Although nasogastric tube placement usua presents few problems, difficulties do arise wheno attempts are made to perform nasogastric intubations in patients with oesophageal strictures, and nasoen-o teric intubation of those with gastric atony. In theö first group of patients, irrespective of whether the stricture is malignant or benign, intubation is usually $\overrightarrow{\vec{O}}$ required either during diagnostic endoscopy or im- $\exists$ mediately following endoscopic dilatation (Keohane,, Attrill and Silk, 1982). In the second group, despite claims to the contrary (Metz, Dilawari and Kellocko 1978; Dobbie and Butterick, 1977), feeding tubes 3 . rarely pass through the pylorus spontaneously, and have to be placed in the jejunum or duodenum at endoscopy.

\section{Nasoenteric feeding}

In certain patients with neurological disorders of swallowing mechanism (e.g. motor neurone disease, , pseudobulbar palsy) or gastric atony, regurgitation or : aspiration of enteric feeds administered nasogastrically necessitates the cessation of nasogastric feeding. Theoretically, these side effects should be circum 0 vented by direct duodenal or jejunal feeding. In these patients it is our current policy to intubate the? duodenum endoscopically with one of the longer 0 weighted tubes. 


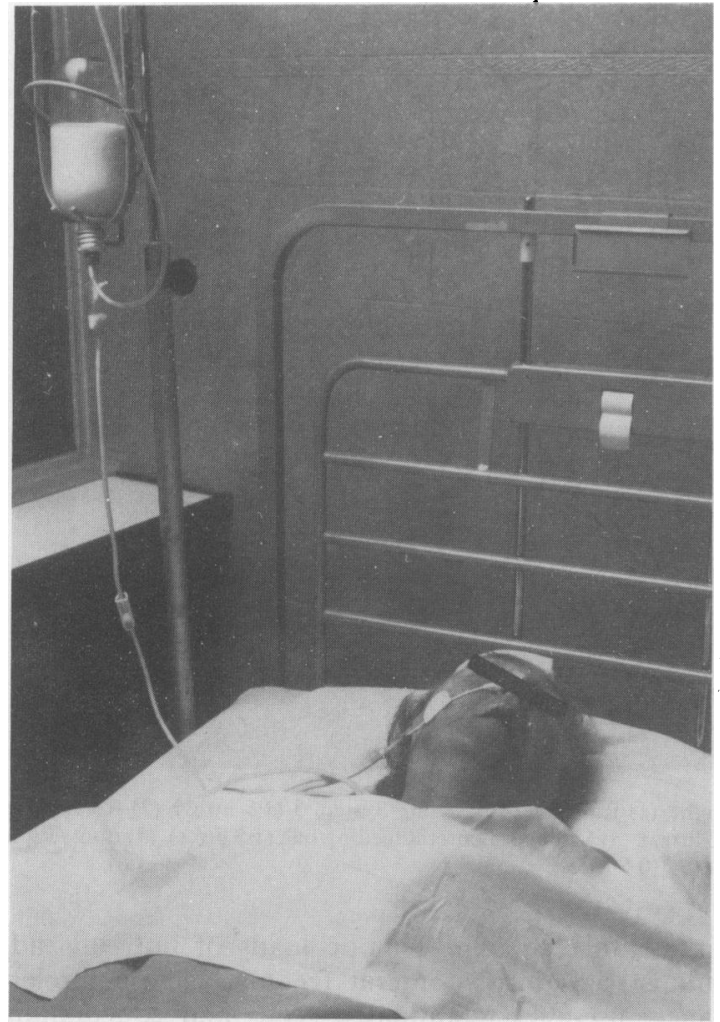

FIG. 2. Enteral feeding of a patient following neurosurgery. Patient is intubated nasogastrically with a fine bore feeding tube, and receiving an enteral diet by constant gravity infusion from a $500 \mathrm{ml}$ glass container via a standard giving set.

\section{Early postoperative nasoenteral feeding}

The recognition that small bowel function returns earlier on in the postoperative period than gastric function has lead to the concept of early postoperative enteral feeding via fine needle catheter jejunostomy or via nasoenteric tubes positioned at the time of laparotomy (Sagar, Harland and Shields, 1979). On theoretical grounds, this would appear to represent an ideal means of providing nutritional support in the early postoperative period, although the data is far from clear in respect of clinical advantages (Young et al., 1978). In most of the published studies 'elemental' rather than polymeric diets were used (for which there appears to be little rationale) and in one controlled study (Sagar et al., 1979) which claims advantages, the only possible benefit (and a questionable one at that) that seems actually to have accrued in the treatment group was that the patients were discharged from hospital sooner than those not receiving nutritional support.

\section{Administration techniques}

Enteric diets are best administered from feed reservoirs via a giving set and feeding tube directly into the stomach, duodenum or jejunum (Fig. 2). There has been a recent proliferation of delivery systems (Fig. 4) and debate exists as to the ideal volume of the food reservoirs. A recent study (Bastow, Allison and Greaves, 1981) indicates that feeds which are mixed in the diet kitchen are subject to significant bacterial contamination (e.g. preparation of standard 'home brew' tube feeds or energy supplementation of other feeds). During administration, bacterial multiplication occurs, so those diets, if used, should not be prepared in volumes of more than 0.5 litres. No significant bacterial contamination

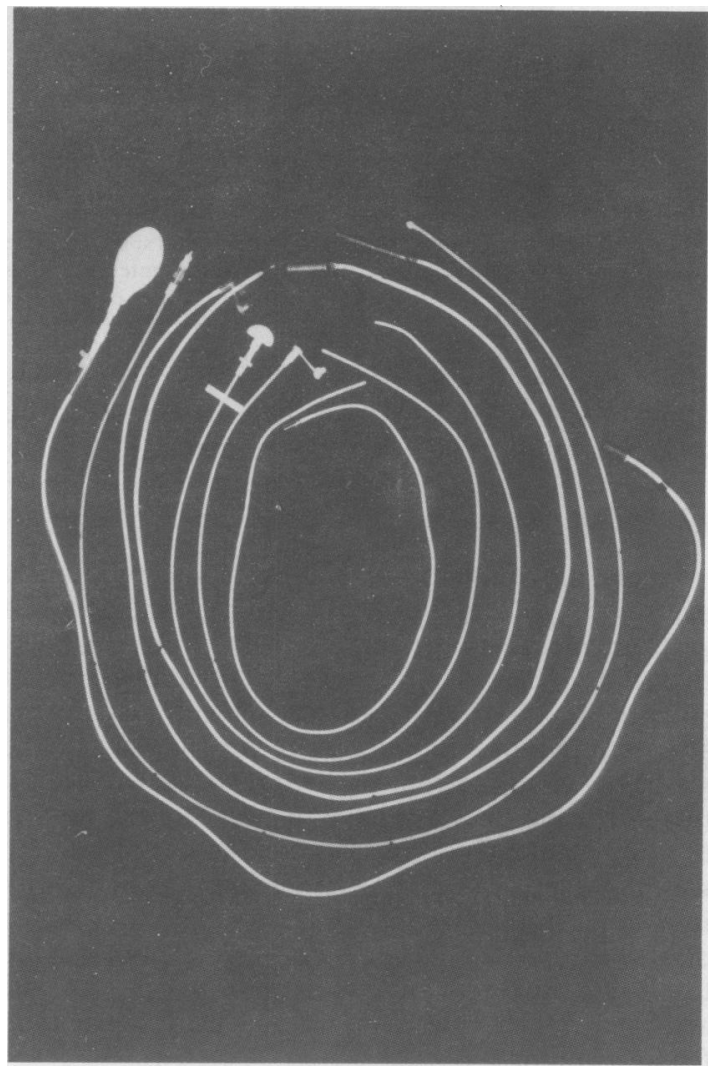

FIG. 3. A selection of commercially available nasogastric and nasoenteric feeding tubes. From inside to outside: (1) Clinifeeding System 1 (Roussel Laboratories: PVC, $70 \mathrm{~cm}$. int. diam $1 \mathrm{~mm}$ ); (2) Entri nasogastric feeding tube (Biosearch: Erythrothane, $81 \mathrm{~cm}$. no. 6 French); (3) Prima enteral feeding tube (Portex; PVC, $85 \mathrm{~cm}, 1.1$ $\mathrm{mm}$ ); (4) Hydromer-Dobbhoff enteric feeding tube (Biosearch; Erythrothane, $109 \mathrm{~cm}$. no. 8 French); (5) Entriflex nasogastric feeding tube (Biosearch; Erythrothane, $91 \mathrm{~cm}$. no. 8 French); (6) Enteral feeding tube (SHS; Silicone, $125 \mathrm{~cm}$. no. 7 French); (7) Duo Tube enteral feeding unit (Argyle; Silicone, $102 \mathrm{~cm}$. no. 8 French). 


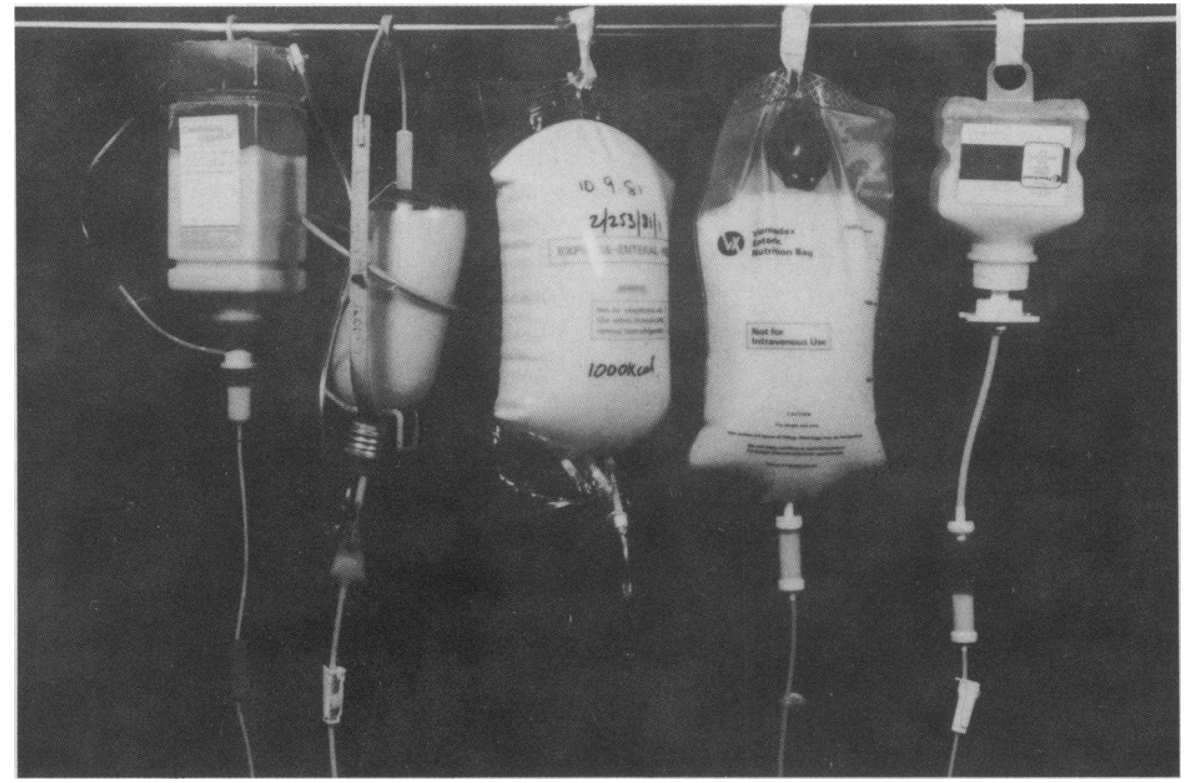

FIG. 4. A selection of enteral feeding bags and reservoirs. From left to right: (1) Roussel Clinifeeding System 3 (1.5 litres); (2) Re-usuable DHSS Winchester container ( 0.5 litres); (3) Express enteral feeding bag ( 2 litres); (4) Viomedex enteral feeding bag (1.5 litres); (5) Boots Flov? Fuser enteral feeding bottle ( 0.5 litres).

of pre-sterilised enteral feeds appears to occur during filling of reservoirs, so if these diets are employed, up to 2 litre volume reservoirs can be used.

\section{Enteral feeding pumps}

In our unit all diets are administered continuously over $24 \mathrm{hr}$, as a means of reducing the incidence of gastrointestinal side effects (see below). In a prospective study (Jones, Payne and Silk, 1980) over $85 \%$ of 80 patients were fed successfully when the diets were administered by simple gravity infusion using the giving-set clamp to control the infusion rate. Clearly, therefore, one does not have to advocate the routine use of an enteral feeding pump. The use of a pump was, however, shown to be beneficial in patients with impaired gastrointestinal function who developed diarrhoea during enteral feeding and a saving of up to 30 min nursing time per patient per day can be achieved if diets are administered using an enteral feeding pump.

\section{Use of starter regimes}

Upper abdominal symptoms including distension, discomfort and colicky pains, as well as diarrhoea, are said to frequently occur if full-strength enteric feeding regimes are introduced too quickly (Silk, 1980). A number of factors have been implicated in the pathogenesis of these side effects. These include intolerance to high osmotic loads of nutrients ministered during enteral feeding, lactose into ere ance, use of contaminated feeds and concomitan antibiotic therapy (Silk, 1983). It has been generall believed that the incidence of these side effects can b. minimized by gradually introducing full-strength enteric feeds over a 3-4 day period by means of 'starter regimes'.

Our most recent controlled studies have however shown that starter regimes in patients with norma gastrointestinal function fed with polymeric diets by constant gravity infusion are unnecessary (Keohane et al., 1984a). Full strength regimes can be prescribeg from the outset, and diarrhoea, which did occur i some $10-15 \%$ of cases, appeared related solely to concomitant oral or parenteral antibiotic therap (Keohane et al., 1984).

\section{Complications of enteral nutrition (Table 9) \\ Tube-related problems}

Complications associated with larger-bore Ryle tubes (oesophageal erosions, haemorrhage and strice tures) have not been reported with the fine bore nasogastric tubes. The fine bore tubes can be passeg into the trachea rather than into the oesophagu范 especially in comatose patients, so care must be takefe to ensure correct positioning before enteric feeding is started. A common problem with the narrow bore 
feeding tube is the ease with which the tube rides up into the oesophagus, or is removed completely by the patient; a significant number of patients on enteric feeding regimens require more than one intubation (Keohane et al., 1983c). Intravenous administration of an enteric feed has been reported but this complication should not occur if feeding tubes and giving sets are used with reversed Luers.

\section{Gastrointestinal side effects}

As mentioned above, diarrhoea, abdominal distention and abdominal pain are common side effects, occurring at some stage during the treatment in up to $25 \%$ of patients receiving enteral nutrition (Jones $e t$ al., 1983). As the most likely cause of these problems is concomitant antibiotic therapy (Keohane et al., 1984), antibiotics should be stopped if clinically possible. If not, symptomatic treatment with loperamide or codeine phosphate, if diarrhoea is the predominant problem, is often effective, and enteral nutrition rarely has to be stopped on account of these problems.

\section{Metabolic complications}

Hyperglycaemia may occur during enteric feeding, caused by excessive sugar intake or insulin resistance associated with trauma and injury. Initially, frequent urine testing for sugar should be performed as well as blood glucose measurement. Electrolyte abnormalities, particularly hypokalaemia, commonly occur during enteral nutrition and are related not only to the feeding regimen, but also to the underlying medical or surgical disorder. Low blood levels of calcium, magnesium, zinc and phosphate can also occur, and supplements may be required.

\section{Abnormalities of liver function}

Abnormal liver function tests have been reported in patients receiving enteral as well as parenteral nutrition, though earlier reports that abnormalities of liver function inevitably occur have not been confirmed. The aetiology of these changes is uncertain. Changes include elevations of alkaline phosphatase, $\gamma$-glutamyl transpeptidase and the hepatocellular enzymes. It is common for minor and intermittent elevations of hepatocellular enzymes to occur and little significance need be attached to this. Occasionally a marked and persistent elevation of alkaline phosphatase has occurred. In our experience the highest levels up to $48 \mathrm{KA}$ units (1000 iu/litre) have been observed before the start of therapy, and histology shows that this is due to marked fatty infiltration, presumably related to associated proteincalorie malnutrition. All tests usually return to normal when enteral nutrition is terminated and we have never had to discontinue enteric feeding on account of any of the above changes.

\section{Conclusions}

A full clinical, biochemical, haematological and immunological assessment of nutritional status should be performed before any form of nutritional support is instituted and baseline values obtained for all other haematological and biochemical measurements. If electrolyte or other abnormalities occur, measurements should be made at frequent intervals. Careful monitoring is important to ensure early identification of possible complications of enteral and parenteral nutrition.

\section{References}

BaKeR, J.P., Detsky, A.S., Wesson, D.E., Wolman, S.L., StewarT, S. Whitewell, J., LANGer, N. \& JeeJeebhoY, K.N. (1982). Nutritional assessment. A comparison of clinical judgement and objective measurements. New England Journal of Medicine, 306, 169.

Bastow, M.D., Allison, S.P. \& Greaves, P. (1981) Study of microbial contamination of nasogastric feeds. In: Proceedings of the 3rd European Congress on Parenteral and Enteral Nutrition. p. 75 .

Bristian, B.R., Blackburn, G.L., Hallowell, E. \& Heddle, R. (1974) Protein status of general surgical patients. Journal of the American Medical Association, 230, 858.

CASEWELL, M.W. (1979) Nasogastric feeds as a source of klebsiella infection for intensive care patients. Research and Clinical Forums 1,101

Collins, J.P., MCCarThy, I.D. \& Hull, G.L. (1979) Assessment of protein nutrition in surgical patients-the value of anthropometrics. American Journal of Clinical Nutrition 32, 1527.

DOBBIE, R.P. \& BUTTERICK, O.D. (1977) Continuous pump/tube enteric hyperalimentation - use in oesophageal disease. Journal of Parenteral and Enteral Nutrition, 1, 100.

Hill, G.L., BlacketT, R.L., Pickfort, I. \& Young, G.A. (1977) Malnutrition in surgical patients. An unrecognized problem. Lancet, i, 689.

HILL, G.L. (1979) Do malnourished patients need nutritional therapy before major surgery? Medical Journal of Australia, 2, 464.

INGENBleEK, Y., VAN DEN SHRIEK H.G., DE NAYER P. \& DE BisSCHER, M. (1975) Albumin, transferrin and thyroxine binding prealbumin/retinol binding protein (TBPA/RBP) complex in assessment of malnutrition. Clinica Chimica Acta, 63, 61 .

JAMES, W.P.T. (1982) Assessment of nutritional status. Medicine International, 15, 663 .

JONES, F. AVERY (1983a) In: Nutrition in Medical Education Report of the British Nutrition Foundation's Task Force on Clinical Nutrition. Ed. J. Gray. June 1983.

JONES, F. AVERY (1983b) In: Nutritional support in hospital practice. Blackwell Scientific Publications, Oxford, London etc. p vi.

JoNES, B.J.M., PAYNe, S. \& SilK, D.B.A. (1980) Indications for pump assisted enteral feeding. Lancet, i, 1057.

JONES, B.J.M., BROWN, B.E., GRIMBLE, G.K. \& SILK, D.B.A. (1981) The formulation of energy dense enteral feeds - the use of high molecular weight glucose polymers. In: Proceedings 3rd European Congress on Parenteral and Enteral Nutrition, p. 75.

JoNes, B.J.M., LeES, R., ANDREWS, J., Frost, P. \& SilK, D.B.A. (1983) Comparison of an elemental and polymeric enteral diet in patients with normal gastrointestinal function. Gut, 24, 78.

JONES, D.C., RICH, A.J., WRIGHT, P.D. \& JOHNSON, I.P.A. (1980) Comparison of proprietary elemental and whole-protein diets in 
unconscious patients with head injury. British Medical Journal, 1, 1493.

Keighley, M.R.S., Mogg, B., Bentley, S. \& Allan, C. (1983) 'Home brew' compared with commercial preparations for enteral feeding. British Medical Journal, 1, 163.

Keohane, P.P., AtTrill, H., Jones, B.J.M., Brown, I., Frost, P. \& SILK, D.B.A. (1983) Influence of lactose and $\mathrm{Cl}$. difficile in the pathogeneisis of enteral feeding associated diarrhoea. Clinical Nutrition, 1, 259.

Keohane, P.P., ATtrill, H. \& Silk, D.B.A. (1982) Endoscopic placement of fine bore nasogastric and nasoenteric feeding tubes. Clinical Nutrition, 1, 245.

Keohane, P.P., AtTrill, H. \& Silk, D.B.A. (1983) Clinical indications for weighted enteral feeding tubes. Clinical Nutrition, $2,27$.

Keohane, P.P., ATtrill, H., Jones, B.J.M. \& Silk, D.B.A. (1983) Limitations and drawbacks of 'fine bore' nasogastric feeding tubes. Clinical Nutrition, 2, 85.

Keohane, P.P., Attrill, H., Love, M., Frost, P. \& Silk, D.B.A (1984) Relation between osmolality of diet and gastrointestinal side effects in enteral nutrition. British Medical Journal, 288, 678.

KORETZ, R.L. \& MEYER, J.H. (1980) Elemental diets-facts and fantasies. Gastroenterology, 78, 393.

LAW, D.K., DUDRICK, S.J. \& ABDON, N.I. (1973) Immunocompetence of patients with protein calorie malnutrition. Effects of nutritional repletion. Annals of Internal Medicine, 79, 545.

Meakins, J.L., Pietsch, J.B., Bubenick, O., Kelly, R., Rode, H., GORDON, J. \& MACLEAN, L.B. (1977) Delayed hypersensitivity: indicator of acquired failure of host defences in sepsis and trauma. Annals of Surgery, 186, 241.
METZ. G., Dilawari, J. \& Kellock, T.D. (1978) Simple techniqu謟 for naso-enteric feeding. Lancet, ii, 454.

MUNRo, H. (1978) Biological limiting factors to parenteral amin acid feeding. In: Advances in Parenteral Nutrition 1978 ed. I. D. Johnston, MTP Press, Lancaster p. 107.

PietsCh, J.B., Meakins, J.L. \& MaClean, L.D. (1977) The delayed hypersensitivity response: application in clinical surgery. Surge? 82. 349.

RUSSELL, R.I. (1975) Elemental diets. Gut, 16, 68.

SaGar, S., Harland, P. \& Shields, R. (1979) Early postoperative feeding with elemental diet. British Medical Journal, 1, 293.

ShetTY, P.S., WatRaSiewicz, K.E., JunG, R.T. \& James, W.P.T (1979) Rapid-turnover transport proteins: an index of subclinica protein energy malnutrition. Lancet, ii, 230.

SILK, D.B.A. (1980) Enteral nutrition. Hospital Update, 6, 761.

SILK, D.B.A. (1983) Nutritional support in hospital practice Blackwell Scientific Publications, Oxford.

Spanier, A.H., Pietsch, J.B., Meakins, J.L., Maclean, L.D. SHIZGAL, H.M. (1976) Relationship between immune competengs and nutrition. Surgical Forum, 27, 332.

WoOlfSON, A.M.J. (1978) Metabolic considerations in nutritional support. Proceedings of Symp. Roy Coll Phys. Research ang Clinical Forum. 1, 35.

Yeung, C.K., Young, G.A., Hackett, A.F. \& Hill, G.L. (1972 Fine needle catheter jejunostomy-an assessment of a ney method of nutritional support after major gastrointestinal surge British Journal of Surgery, 66, 727 